\title{
The Mediterranean diet and nonalcoholic fatty liver disease in individuals at high cardiovascular risk
}

\author{
Seyedeh Tayebeh Rahideh, Farzad Shidfar \\ Department of Nutrition, School of Public Health, Iran University of Medical Sciences, Tehran, Iran \\ Correspondence to: Farzad Shidfar. Department of Nutrition, School of Public Health, Iran University of Medical Sciences, Tehran, Iran. \\ Email: farzadshidfar@yahoo.com. \\ Comment on: Pintó X, Fanlo-Maresma M, Corbella E et al. A mediterranean diet rich in extra-virgin olive oil is associated with a reduced prevalence \\ of nonalcoholic fatty liver disease in older individuals at high cardiovascular risk. J Nutr 2019;149:1920-9.
}

Submitted Dec 08, 2019. Accepted for publication Dec 23, 2019.

doi: 10.21037/hbsn.2019.12.09

View this article at: http://dx.doi.org/10.21037/hbsn.2019.12.09

Non-alcoholic fatty liver disease (NAFLD) is the most common cause of chronic liver disease in the world, affecting about $30 \%$ of the world's adult population $(1,2)$. The disease ranges from simple steatosis (SS) to nonalcoholic steatohepatitis (NASH) (3). The prevalence of NAFLD is higher in patients with cardio metabolic risk and cardiac metabolic conditions are associated with increased risk of cardiovascular disease and type 2 diabetes. It is found in $50 \%$ of people with hypertension, $70 \%$ of diabetics and $90 \%$ of obese people (4). According to the "multiple-hit" theory of insulin resistance, lipotoxicity, nutritional factors, gastrointestinal microbiome, epigenetic and genetic factors are widely involved in the pathogenesis of this disease (5). As a result of obesity, visceral adipose tissue secretes adipokines, such as TNF- $\alpha$ and interleukins, which lead to vascular inflammation and insulin resistance (6). The first physiological event in NAFLD is insulin resistance. The severity of insulin resistance is associated with the severity of liver injury, from benign steatosis to advanced NASH and fibrosis (7).

Lifestyle changes such as nutritional intervention and physical activity are recommended to reduce intrahepatic fat and improve NAFLD (8). The Mediterranean diet (MD) has been shown to reduce the incidence and about $33 \%$ risk of mortality rate of cardiovascular disease $(7,9)$. This plant-based diet has a high MUFA to SFA ratio of 30-40\% of daily energy (10). MD is a model of consuming fruits and vegetables, olive oil, nuts, whole grains, fish, low-fat dairy products, limited consumption of red meat (7). The protective effects of MD are provided by extra virgin olive oil (EVOO), which contains polyphenol, tocopherol and carotenoids, which increase hepatic steatosis by increasing lipid oxidation and inhibiting lipogenesis (4). It also plays a role in improving NAFLD by improving lipid profiles, insulin resistance and obesity-induced inflammation (4). Olive oil-rich MD reduces liver fat up to $40 \%$ in NAFLD patients in clinical trials (3).

In the article published in Journal of Nutrition in issue 11, November 2019, Pintó et al. showed that EVOO-rich MD reduced the prevalence of NAFLD in people with high cardiovascular risk (11). This study was performed on a subgroup of PREvencióncon DIeta MEDiterránea (PREDIMED) trials designed in a multicenter, randomized controlled, parallel fashion. The PREDIMED cohort aimed at the effect of MD on primary prevention of cardiovascular disease continued from 2003 to 2011. This study, unlike other interventional studies, provided the same opportunity for long-term follow-up in people with cardiovascular risk under Mediterranean conditions (12).

In the study of Pintó et al., 109 individuals at risk for cardiovascular disease including type 2 diabetes and having at least 3 cardiovascular risk factors but without CVD were included. Subjects were divided into three intervention groups including MD + EVOO receiving EVOO one liter per week, $\mathrm{MD}$ + nuts receiving $30 \mathrm{~g}$ walnut, almond and hazelnut daily, and control group (advice to reduce all dietary fat) for 3 years. Cardio metabolic risk was similar in all three intervention groups. Hepatic steatosis, evaluated with NMR, was significantly different between the groups $(\mathrm{P}=0.027)$ and was $8.8 \%$ in the $\mathrm{MD}+\mathrm{EVOO}$ group compared to $3.33 \%$ in the other groups. The ratio of 12 
(S)-hydroxyeicosatetraenoic acid (12-HETE) to creatinine indicating inflammatory status and oxidative stress was lower in the MD + EVOO group than in the other two groups. Adherence to diet improved in both MD groups over three years but decreased in the control group (11).

In some clinical trials, the effect of MD on fat loss and weight-independent steatosis has been observed $(3,13)$. In Pintó et al. study, the effect of MD + EVOO without energy restriction and no significant reduction changes over three years resulted in NAFLD improvement. Although BMI changes were significant between the two groups with and without steatosis, no clinically significant differences were observed (11). In spite of no significant differences in HOMA-IR among groups, the level of fasting glucose was better to be mentioned and discussed.

Although it is not clear which components of MD are the major responsible for these effects, the beneficial role of polyphenols and EVOO has been reported (14).

Finally, by changing the components of the MD diet, we can see its beneficial effects on steatosis as a major NAFLD criterion, but further studies are needed to identify the mechanism of these effects on other metabolic factors.

\section{Acknowledgments}

Funding: None.

\section{Footnote}

Provenance and Peer Review: This article was commissioned by the editorial office, Hepatobiliary Surgery and Nutrition. The article did not undergo external peer review.

Conflicts of Interest: Both authors have completed the ICMJE uniform disclosure form (available at http://dx.doi. org/10.21037/hbsn.2019.12.09). The authors have no conflicts of interest to declare.

Ethical Statement: The authors are accountable for all aspects of the work in ensuring that questions related to the accuracy or integrity of any part of the work are appropriately investigated and resolved.

Open Access Statement: This is an Open Access article distributed in accordance with the Creative Commons Attribution-NonCommercial-NoDerivs 4.0 International License (CC BY-NC-ND 4.0), which permits the noncommercial replication and distribution of the article with the strict proviso that no changes or edits are made and the original work is properly cited (including links to both the formal publication through the relevant DOI and the license). See: https://creativecommons.org/licenses/by-nc-nd/4.0/.

\section{References}

1. Abenavoli L, Boccuto L, Federico A, et al. Diet and NonAlcoholic Fatty Liver Disease: The Mediterranean Way. Int J Environ Res Public Health 2019. doi: 10.3390/ ijerph16173011.

2. Zheng J, Zhou Y, Zhang K, et al. Association between nonalcoholic fatty liver disease and subclinical atherosclerosis: a cross-sectional study on population over 40 years old. BMC Cardiovasc Disord 2018;18:147.

3. Ryan MC, Itsiopoulos C, Thodis T, et al. The Mediterranean diet improves hepatic steatosis and insulin sensitivity in individuals with non-alcoholic fatty liver disease. J Hepatol 2013;59:138-43.

4. Della Pepa G, Vetrani C, Lombardi G, et al. Isocaloric dietary changes and non-alcoholic fatty liver disease in high cardiometabolic risk individuals. Nutrients 2017;9:1065.

5. Katsagoni CN, Papatheodoridis GV, Ioannidou P, et al. Improvements in clinical characteristics of patients with non-alcoholic fatty liver disease, after an intervention based on the Mediterranean lifestyle: a randomised controlled clinical trial. Br J Nutr 2018;120:164-75.

6. Ozturk K, Uygun A, Guler AK, et al. Nonalcoholic fatty liver disease is an independent risk factor for atherosclerosis in young adult men. Atherosclerosis 2015;240:380-6.

7. Ratziu V, Ghabril M, Romero-Gomez M, et al. Recommendations for management and treatment of nonalcoholic steatohepatitis. Transplantation 2019;103:28-38.

8. Gelli C, Tarocchi M, Abenavoli L, et al. Effect of a counseling-supported treatment with the Mediterranean diet and physical activity on the severity of the non-alcoholic fatty liver disease. World J Gastroenterol 2017;23:3150-62.

9. Sofi F, Casini A. Mediterranean diet and non-alcoholic fatty liver disease: New therapeutic option around the corner? World J Gastroenterol 2014;20:7339-46.

10. Zelber-Sagi S, Salomone F, Mlynarsky L. The Mediterranean dietary pattern as the diet of choice for non-alcoholic fatty liver disease: Evidence and plausible mechanisms. Liver Int 2017;37:936-49.

11. Pintó X, Fanlo-Maresma M, Corbella E, et al. A Mediterranean Diet Rich in Extra-Virgin Olive Oil Is Associated with a Reduced Prevalence of Nonalcoholic 
Fatty Liver Disease in Older Individuals at High

Cardiovascular Risk. J Nutr 2019;149:1920-9.

12. Martínez-González MÁ, Corella D, Salas-Salvadó J, et al. Cohort profile: design and methods of the PREDIMED study. Int J Epidemiol 2012;41:377-85.

13. Properzi C, O'Sullivan TA, Sherriff JL, et al. Ad Libitum
Mediterranean and Low-Fat Diets Both Significantly Reduce Hepatic Steatosis: A Randomized Controlled Trial. Hepatology 2018;68:1741-54.

14. Anania C, Perla FM, Olivero F, et al. Mediterranean diet and nonalcoholic fatty liver disease. World J Gastroenterol 2018;24:2083-94.

Cite this article as: Rahideh ST, Shidfar F. The mediterranean diet and nonalcoholic fatty liver disease in individuals at high cardiovascular risk. HepatoBiliary Surg Nutr 2020;9(5):654-656. doi: 10.21037/hbsn.2019.12.09 